\title{
Avaliação objetiva no diagnóstico de broncoconstrição induzida pelo exercício
}

\section{Objective measurements for diagnosis of exercise-induced bronchoconstriction}

Rev Port Imunoalergologia $2019 ; 27$ (4):309-325

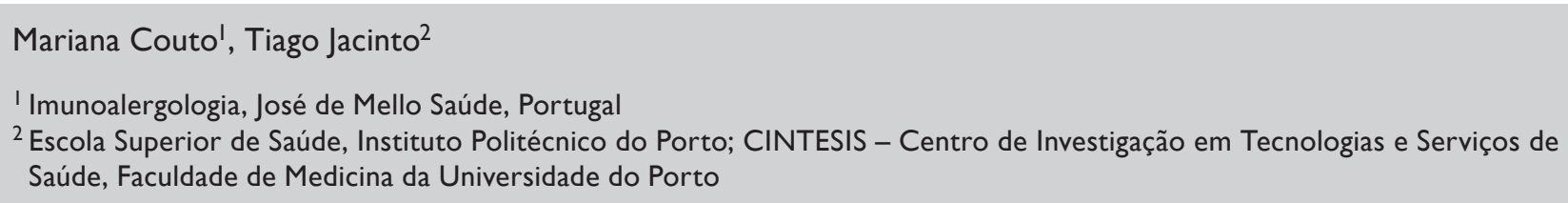

\section{RESUMO}

A broncoconstrição induzida pelo exercício (BIE) define-se como o aumento transitório da resistência das vias aéreas resultante da obstrução brônquica que ocorre após esforço físico. É uma entidade clínica muito frequente, que importa diagnosticar corretamente de forma a prevenir a resposta broncoconstritora ao esforço, de modo a que esta não constitua restrição à escolha de uma atividade física ou limitação ao nível do desempenho desportivo. A história clínica pode ser extremamente sugestiva, porém, são frequentes tanto situações de sobrediagnóstico de asma como de subdiagnóstico de BIE. Assim sendo, e face à importância do diagnóstico exato, pretende-se com o presente artigo apresentar os exames complementares no diagnóstico de BIE, abordando a sua utilidade e aplicabilidade.

Palavras-chave: Asma, broncoconstrição, diagnóstico, espirometria, exercício, hiperventilação voluntária eucápnica, manitol, provocação. 


\section{ABSTRACT}

Exercise-induced bronchoconstriction (EIB) is defined as the transient increase in airway resistance resulting from bronchial obstruction that occurs after physical exertion. It is a very frequent clinical entity that must be correctly diagnosed in order to prevent the bronchoconstrictive response to the exercise, so that it does not restrict the choice of a physical activity or limits the sports performance. The clinical history can be extremely suggestive, however, both overdiagnosis of asthma and underdiagnosis of EIB are frequent. Therefore, and due to the importance of an exact diagnosis, this article intends to present the complementary exams in the diagnosis of EIB, addressing its usefulness and applicability.

Key-words: Asthma, bronchoconstriction, diagnosis, exercise, eucapnic voluntary hyperventilation, mannitol, provocation, spirometry.

\section{INTRODUÇÃO}

A asma é uma doença inflamatória crónica das vias aéreas que origina episódios recorrentes de dispneia ("falta de ar"), pieira, tosse e aperto torácico, sintomas causados por obstrução generalizada, mas variável, das vias aéreas que é reversível espontaneamente ou com tratamento'. O exercício é um conhecido estímulo físico capaz de desencadear obstrução das vias aéreas e consequentes sintomas respiratórios.

A broncoconstrição induzida pelo exercício (BIE) define-se como o aumento transitório da resistência das vias aéreas resultante da obstrução brônquica que ocorre após esforço físico²; quando tal manifestação ocorre em indivíduos com asma, pode designar-se por asma induzida pelo exercício (AIE), embora alguns autores defendam a designação de BIE com asma ${ }^{3}$. A BIE é uma entidade clínica muito frequente, que se estima ocorrer em 5 a $20 \%$ da população geral, sendo que em doentes asmáticos pode ocorrer em até $90 \%$. É ainda mais frequente em idade pediátrica, com uma prevalência de 3 a $35 \%$ em idades inferiores aos 16 anos, estando provavelmente associada à maior atividade física própria deste grupo etário4-II. Pode iniciar-se em qualquer idade, quer na infância, quer na idade adulta.
Discute-se atualmente a ocorrência de BIE num número significativo de indivíduos sem asma, onde se incluem alguns casos específicos de atletas de alta competição ${ }^{3}$. Nestes casos, que podem ter uma prevalência de $30-70 \%{ }^{4}$, há situações em que não se verifica a existência de asma, mas apenas $\mathrm{BIE}^{12}$.

Os sintomas podem incluir tosse, pieira, dispneia, opressão torácica ou cansaço, que surgem durante e principalmente após cessar o esforço. A resposta máxima ocorre geralmente 3 a 10 minutos após o esforço físico, sendo habitual uma recuperação espontânea num intervalo de 30 a 60 minutos $^{2}$. Neste sentido, a história clínica pode ser extremamente sugestiva, sobretudo se os referidos sintomas são resolvidos ou atenuados com a administração terapêutica ou preventiva de um broncodilatador $\beta 2$-agonista. No entanto, uma consideração importante para os médicos quando o doente apresenta sintomas respiratórios desencadeados pelo exercício é se o diagnóstico apropriado é BIE em doente com asma mal controlada ou apenas BIE, já que a abordagem nas duas situações pode ser diferente. É crucial evitar o sobrediagnóstico de asma e consequente sobretratamento ${ }^{6}$, pelo que a confirmação diagnóstica deve requerer a documentação objetiva e detalhada da obstrução das vias aéreas basal ou após prova de provocação². 
É de notar que no caso dos atletas de alta competição, o diagnóstico é na maior parte das vezes um desafio clínico, porque, ao contrário de outros doentes, nesta população as queixas e os sintomas são quase ausentes ou muito frustres, sendo raras as crises graves de asma como habitualmente são reconhecidas, e os sintomas após o exercício podem passar facilmente despercebidos. Por outro lado, tratando-se ou não de atletas, não será de mais referir a importância do diagnóstico diferencial com outras patologias que podem assemelhar-se à asma, ou mesmo coexistir com a asma.

Assim sendo, e face à importância do diagnóstico exato, pretende-se com esta revisão apresentar os exames complementares no diagnóstico de broncoconstrição induzida pelo exercício, abordando a sua utilidade e aplicabilidade.

\section{ESPIROMETRIA}

\section{Definição e metodologia}

A espirometria (do Latim spirare - respirar) é uma avaliação fisiológica que mede a quantidade de ar inspirada e expirada por um indivíduo em função do tempo. Permite, assim, medir volumes de ar e a velocidade com que $o$ ar entra e sai nas vias aéreas através da boca.

Os parâmetros medidos mais importantes são a capacidade vital forçada (FVC - do inglês forced vital capacity) e o volume expiratório máximo no $1 .{ }^{\circ}$ segundo $\left(\mathrm{FEV}_{1}\right.$, do inglês forced expiratory volume). A FVC é quantidade total de ar que um indivíduo consegue expirar, de forma forçada, numa inspiração máxima; por outras palavras, representa o volume total de ar que um indivíduo consegue mobilizar. O FEV, representa o volume de ar que é expirado no primeiro segundo de uma manobra expiratória forçada. Estes dois parâmetros são usualmente analisados em conjunto com a razão entre eles $\mathrm{FEV}_{\mathrm{l}} / \mathrm{FVC}$, que representa a proporção da FVC que é expirada no primeiro segundo da manobra forçada. Sendo uma avaliação relativamente simples, é fundamental que seja sempre assegurada a sua correta execução através da aplicação de parâ- metros de aceitabilidade e repetibilidade intermanobras expiratórias forçadas. A correta execução técnica da espirometria é uma garantia da validade dos valores obtidos, permitindo assim uma interpretação adequada ${ }^{13}$.

A interpretação dos parâmetros obtidos é feita através da sua comparação com valores de referência, usualmente calculados a partir de equações cujas variáveis explanatórias são o sexo, a idade e a altura ${ }^{14}$.

\section{Utilidade e limitações}

A espirometria é útil na deteção de obstrução brônquica que é tipicamente manifestada por um valor de $\mathrm{FEV}$, e de $F E V_{1} / F V C$ abaixo do limite inferior da normalidade (LIN).

A obstrução brônquica pode estar presente nos casos em que a BIE surge no contexto de asma mal controlada, mas é pouco provável que se evidencie em casos de BIE isolada.

Uma limitação da espirometria, principalmente na interpretação dos valores obtidos, surge nas equações de referência que são utilizadas para estimar os valores esperados para cada parâmetro. As equações de referência são derivadas em estudos com amostras de indivíduos saudáveis não fumadores que nunca ou raramente consideram a prática de exercício ou a atividade física. Assim, no caso específico dos atletas, devido ao elevado treino aeróbio, os valores que apresentam dos diversos parâmetros espirométricos são frequentemente superiores aos valores considerados "normais". Na prática, a comparação com os valores considerados normais limita a utilidade da espirometria nestas situações porque, apesar de os valores estarem dentro desta dita "normalidade", na realidade representam um défice em relação ao que seria expectável para um atleta ${ }^{15}$.

\section{PROVA DE BRONCODILATAÇÃO}

A prova de broncodilatação realiza-se para avaliar a resposta do calibre das vias aéreas a um fármaco broncodilatador. A escolha do fármaco, modo de administra- 
ção ou dose pode variar, embora a mais comum seja a administração de $400 \mathrm{mcg}$ de salbutamol MDI via câmara expansora; outros fármacos a considerar são a terbutalina, o formoterol e o brometo de ipratrópio ${ }^{13}$.

A prova de broncodilatação é considerada positiva se se observar um aumento do $F E V_{\text {, de }} 12 \%$ e $200 \mathrm{~mL}$ em relação à avaliação basal após a inalação de broncodilatador $^{16}$. Suporta o diagnóstico de asma, uma vez que confirma a reversibilidade das vias aéreas muito própria dessa patologia. Não se correlaciona propriamente com as queixas de esforço, mas quando se observa reversibilidade é expectável a presença de hiperreatividade brônquica (HRB) e, com elevada probabilidade, estará presente $\mathrm{BIE}^{17}$.

\section{PROVAS DE PROVOCAÇÃO BRÔNQUICA}

As provas de provocação brônquica consistem em aplicar um determinado estímulo ao sistema respiratório e medir a sua resposta através de uma avaliação objetiva, válida e reprodutível. Pressupõem sempre a realização de uma espirometria basal e repetição da espirometria após o estímulo para documentar se há queda do $\mathrm{FEV}_{\text {, }}$ em relação ao basal. $O$ valor de queda considerado significativo é variável, dependendo da prova (por exemplo, $20 \%$ para a prova de metacolina, $10 \%$ para a prova com exercício e hiperventilação voluntária eucápnica, 15\% para a prova com manitol, etc). $O$ estímulo pode ser administrado em doses crescentes (provas incrementais - por exemplo metacolina ou manitol) ou de forma única (por exemplo exercício); nas provas incrementais há realização de espirometria a cada dose, nas provas com dose única há realização de espirometrias no final. Os principais objetivos das broncoprovocações são documentar a presença e avaliar e gravidade de HRB, característica muito comum nos indivíduos com asma, que se pode definir como uma resposta exacerbada dos brônquios a um estímulo que é considerado normal. Essa resposta exacerbada poderá passar por aumento de produção de secre- ções, libertação de mediadores inflamatórios e alteração do tónus do músculo liso brônquico; isto será traduzido em obstrução brônquica e consequentemente diminuição

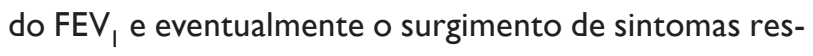
piratórios. Importante referir que apesar de a HRB ser característica incontornável da asma, a gravidade da hiperreatividade observada num determinado indivíduo não reflete necessariamente a gravidade da sua asma.

Ao longo da história, foram principalmente dois os eventos que levaram ao desenvolvimento das provas de provocação para identificar HRB. O primeiro foi no início dos anos 60, com o reconhecimento de que crianças com asma podem desencadear crises com o exercício físico, um estímulo não imunológico ${ }^{18,19}$. Mais tarde, em 1968, outro evento marcante foi a comercialização do cromoglicato de sódio em dispositivo de pó seco para inalação: o modo de ação deste fármaco observado nos estudo in vitro sugeria que estabilizava a membrana do mastócito, inibindo a libertação imunológica (lgE mediada) de histamina em resposta aos alergénios inalados; apesar de não ter efeito direto sobre as células do músculo liso nas vias aéreas, ainda assim era muito eficaz em prevenir tanto a resposta precoce como tardia das vias aéreas aos alergénios inalados ${ }^{20,21}$. Rapidamente se reconheceu o potencial benefício deste fármaco na BIE, e o passo seguinte da investigação focou-se em desenvolver um teste estandardizado com o exercício que permitisse identificar alterações na função respiratória e medir essas alterações ${ }^{22-25}$. A prova de provocação com exercício foi, portanto, a primeira prova de provocação brônquica a ser desenvolvida.

\section{Tipos de estímulos}

Diversos estímulos podem ser utilizados para as provas de provocação brônquica. Estes estímulos são classificados em diretos e indiretos, de acordo com o mecanismo principal de ação através do qual causam broncoconstrição ${ }^{26}$. Esta classificação enfatiza a heterogeneidade da resposta das vias aéreas aos diferentes estímulos e ajuda a compreender as diferenças na sensibilidade e especificidade 
das provas e o efeito do tratamento sobre a HRB ${ }^{26-28}$. Portanto, os resultados das diferentes provas de provocação brônquicas devem ser interpretados tendo em conta o estímulo utilizado, a fase da doença e o tratamento. A principal diferença entre as provas de provocação diretas e indiretas, na prática clínica, é a sensibilidade e especificidade para o diagnóstico de asma.

Os estímulos diretos causam broncoconstrição atuando diretamente sobre células efetoras, como as células do músculo liso, as células endoteliais vasculares dos brônquios e/ou as células produtoras de muco ${ }^{27}$ (Figura I). O principal estímulo direto usado na prática clínica é a metacolina, embora em alguns países se utilize também a histamina.

Os estímulos indiretos causam broncoconstrição ao atuarem em células inflamatórias e/ou neuronais que ao serem ativadas produzem mediadores que interagem e atuam secundariamente sobre as células efetoras ${ }^{27,29}$ (Figura I). As principais provas indiretas utilizam como estímulo o exercício, o manitol, solutos hipertónicos ou a hiperventilação voluntária eucápnica (HVE).

Importa ter em conta os mecanismos que levam à ocorrência de BIE, de forma a melhor compreender a lógica subjacente à escolha dos estímulos para a broncoprovocação (Figuras 2 e 3). Os mecanismos clássicos subjacentes incluem as hipóteses: I) osmótica, por desidratação das vias aéreas, e 2) térmica, por perda de calor das vias aéreas. Devido à elevada ventilação que ocorre durante o exercício, ocorre inalação de ar frio e seco, que provoca a evaporação da água da superfície das vias aéreas, resultando em contração celular e libertação de mediadores inflamatórios que causam a contração do músculo liso brônquico (Figura 2). No caso dos atletas, o modelo explicativo provavelmente ainda inclui a interação entre fatores ambientais e fatores de risco pessoais ${ }^{30}$.

As provas mais precisas para avaliar a BIE são a provocação com exercício, com solutos hiperosmolares, manitol e metacolina e a hiperventilação voluntária eucápnica $^{31,32}$, e por isso são as abordadas no presente trabalho.

\section{Provocações diretas}

A metacolina é um dos estímulos diretos mais utilizados para a realização de provas de provocação brônquica e é preferencialmente usado em vez da histamina, pela

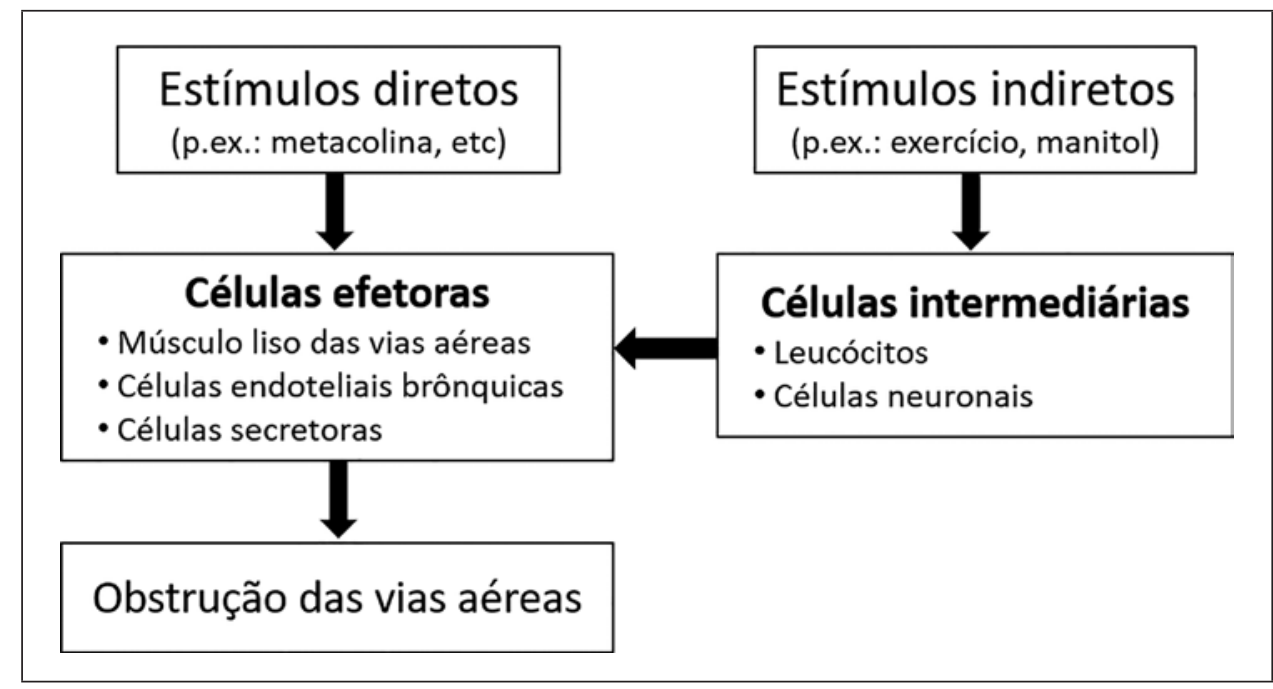

Figura I. Mecanismos de ação dos estímulos diretos e indiretos utilizados nas provas de provocação brônquica 


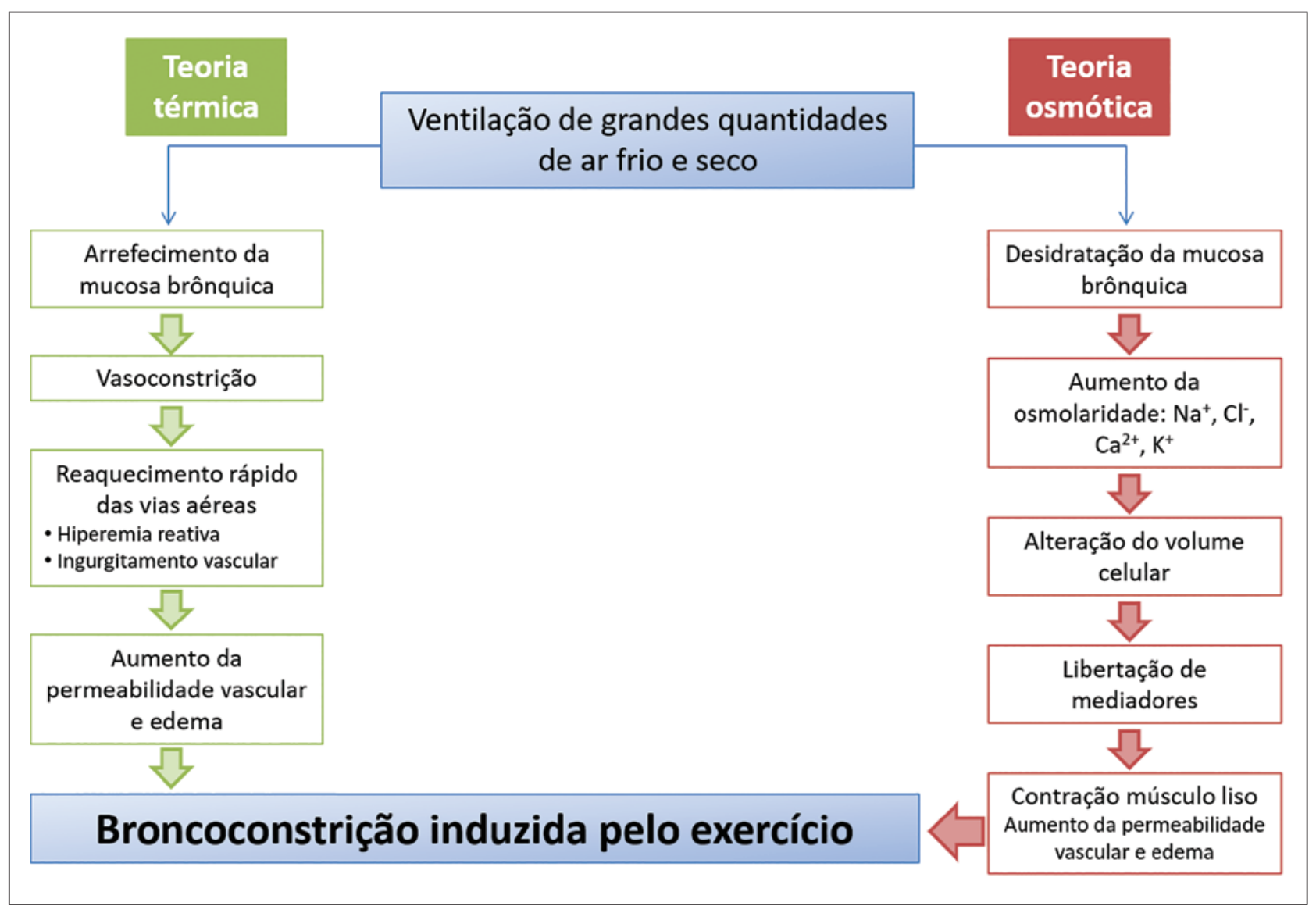

Reproduzido com autorização de Couto M et al. Doenças alérgicas na prática desportiva. Rev Port Imunoalergologia 2017;25:259-75.

Figura 2. Teorias clássicas explicativas da ocorrência de broncoconstrição induzida pelo exercício

menor ocorrência de efeitos secundários e maior reprodutibilidade de resultados. A metacolina é um derivado sintético do neurotransmissor endógeno acetilcolina. A prova de metacolina é incremental e consiste na inalação de doses crescentes de metacolina, através de nebulização com um dosímetro; após cada dose de metacolina administrada, é repetida a espirometria. A prova termina ao atingir-se a dose máxima do protocolo ou quando se verifica queda $\mathrm{FEV}_{1} \geq 20 \%$, comparativamente ao basal, neste caso determinando a positividade da prova. Para uma revisão mais aprofundada desta técnica aconselha-se o documento de consenso recente da European Respiratory Society (ERS) ${ }^{33}$.

\section{Utilidade e limitações}

As provas com estímulos diretos, como a histamina ou metacolina, são extremamente sensíveis para diagnosticar asma. No entanto, estes estímulos carecem de especificidade, tanto em diferenciar asma de normalidade como a asma de outras patologias respiratórias obstrutivas $^{34,35}$. Assim sendo, uma prova positiva com estímulo direto num doente sintomático não confirma asma, mas pelo contrário uma prova negativa em doente sintomático tem elevado valor preditivo negativo, permitindo excluir esse diagnóstico.

No caso específico da BIE, tem sido reportada uma sensibilidade baixa da prova de metacolina ${ }^{36}$; por isso, 


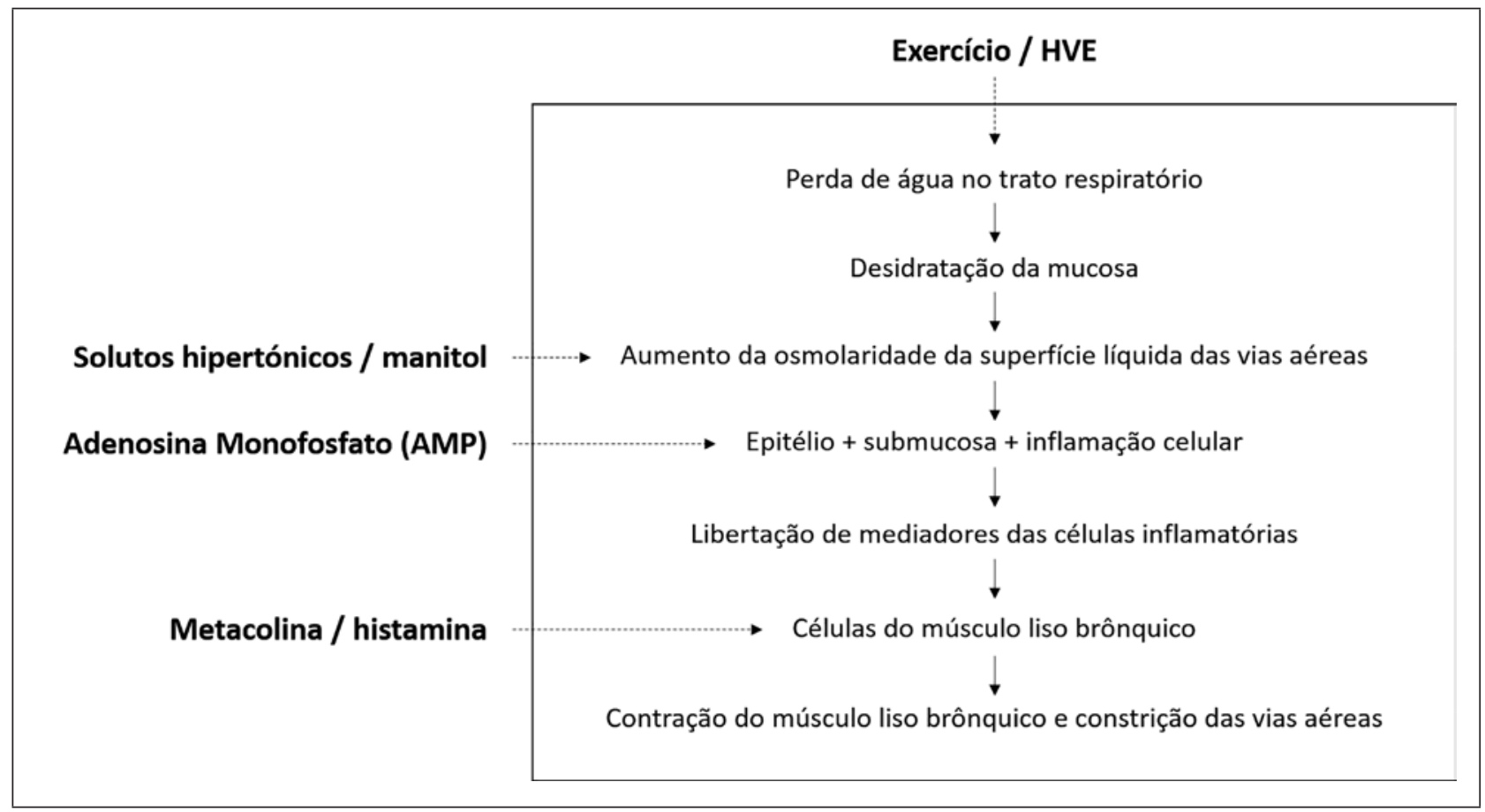

Figura 3. Mecanismos de ação das provas de provocação brônquicas indiretas

uma prova com metacolina negativa não descarta completamente BIE, e poderá ser necessário considerar um estímulo indireto para avaliação adicional ${ }^{32,37-39}$.

Estudos recentes têm demonstrado que até $50 \%$ dos indivíduos com suspeita de asma diagnosticados com base numa prova de provocação com exercício não tinham positividade na prova de metacolina ${ }^{36}$. Portanto, a ausência de HRB a estímulos diretos parece ser frequente, tanto em situações de BIE isolada como em diagnósticos recentes de asma com sintomas de esforço, pelo que devido ao crescente número de estudos que reportam falhas nas provas diretas para diagnóstico de $\mathrm{BIE}$, as guidelines mais recentes não as recomendam para essa finalidade 2,17 .

\section{Provocações indiretas}

Uma revisão recente explora exaustivamente os métodos de realização das provas de provocação com estímulos indiretos ${ }^{34}$ e por isso a técnica metodológica sub- jacente a cada prova não será abordada em profundidade neste trabalho.

Os estímulos indiretos são utilizados nas provas de provocação devido à sua elevada especificidade para identificar indivíduos com asma ativa e para avaliar a eficácia do tratamento com fármacos anti-inflamatórios ${ }^{26-28}$. A principal vantagem dos estímulos indiretos é a sua capacidade de atuar em várias células diferentes, sendo que uma grande variedade de substâncias e mediadores contribuem para a constrição das vias aéreas (por exemplo, histamina, leucotrienos, prostaglandinas e neuropéptidos), o que torna a resposta mais semelhante à broncoconstrição que se desenvolve naturalmente durante as atividades de vida diárias, nomeadamente as que envolvem exercício físico $^{28,40,41}$. Uma vez que os estímulos indiretos têm maior especificidade, outra vantagem da sua utilização é a quase ausência de resultados falsos-positivos; desta forma, têm maior interesse em estudos epidemiológicos para determinar prevalência de asma ${ }^{28,42}$. Tem sido sugerido que os 
estímulos indiretos refletem melhor o grau de inflamação brônquica e por isso teriam mais utilidade do que os estímulos diretos para avaliar e monitorizar a resposta aos fármacos anti-inflamatórios ${ }^{27,43,44}$. Vamos abordar em particular a fundamentação subjacente a cada prova, a sua história, bem como as utilidades e limitações de cada, especificamente em relação a BIE.

\section{Prova de broncoprovocação com exercício}

Como já foi referido, o exercício foi o primeiro estímulo a ser reconhecido e utilizado em provas de broncoprovocação. O primeiro protocolo foi desenvolvido em crianças nos EUA e consistia em pedalar em cicloergómetro durante 5 minutos a uma intensidade suficiente para atingir um batimento cardíaco de 180 bpm ${ }^{22,45}$. A máxima queda

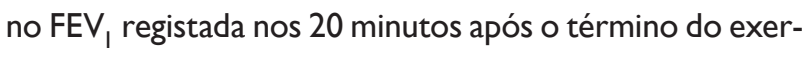
cício expressa em percentagem do previsto era então utilizada para medir a resposta e assim classificar a prova. A resposta era classificada em ligeira se queda $\mathrm{FEV}_{1}<10 \%$, moderada entre $10-25 \%$ e grave se queda $\mathrm{FEV}_{1}>25 \%$.

Uma vez que a corrida foi identificada como sendo um estímulo broncoconstritor mais potente do que pedalar, foram desenvolvidos posteriormente protocolos utilizando tapete ${ }^{46,47}$. Além do tipo de exercício, também a intensidade e a duração foram mais tarde identificadas como parâmetros importantes, bem como o intervalo entre as provas, quando estas eram repetidas ${ }^{23,48}$. Muitas vezes nessa altura era utilizado o PEF, em vez do $\mathrm{FEV}_{1}$, porque podia ser medido rapidamente durante o exercício e assim permitia também documentar uma queda da função respiratória durante o exercício, além da documentada após o término ${ }^{49,50}$.

Em 1974 publicava-se o primeiro consenso que reunia os resultados da investigação nesta área e onde se identificavam alguns pontos-chave. Apesar de algumas vantagens técnicas, a utilização de cicloergómetro era reportada como tendo menor sensibilidade para identificar $\mathrm{AlE}^{51}$. Confirmava-se a utilização preferencial do tapete para corrida e recomendava-se 6 minutos de corrida com gradiente de $10 \%$ a 5 km/h. Em 1975 reportava-se uma queda no $\mathrm{FEV}_{1}$ de $15 \%$ como anormal $^{52}$, embora estudos posteriores tenham identificado $10 \%$ como o melhor cut-off para diagnóstico de $\mathrm{AlE}^{53}$.

Enquanto os protocolos estandardizados para broncoprovocação com exercício em crianças foram publicados no Reino Unido em meados da década de 1970 23,48,54, para adultos as primeiras guidelines clínicas só foram publicadas em 1979 nos EUA ${ }^{55}$ e recomendavam a monitorização eletrocardiográfica e um protocolo com gradiente progressivo ${ }^{56}$.

Posteriormente verificou-se que a alteração da humidade, temperatura e velocidade do vento poderiam ser responsáveis por maior suscetibilidade a $\mathrm{BIE}^{57,58}$. Vários estudos nos anos seguintes demonstraram a influência do ar seco e do ar frio na ocorrência de $\mathrm{AlE}^{59-74}$, tendo contribuído para o estabelecimento do modelo etiopatogénico da doença (representado na Figura 2).

As recomendações e protocolos para identificar BIE na prática clínica são atualizados periodicamente pelas várias sociedades científicas internacionais. Resumidamente, para identificar BIE a duração do exercício deve ser 6 a 8 minutos e a carga de exercício, em corrida ou bicicleta, de intensidade suficiente para elevar a ventilação a 40-60\% da ventilação voluntária máxima (MVV), sendo $\mathrm{MVV}=35 \times \mathrm{FEV}_{1}$; essa intensidade deve ser mantida $4 \mathrm{mi}-$

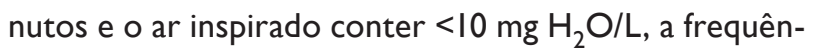
cia cardíaca deve ser monitorizada continuamente e, em idades superiores a 40 anos, deve realizar-se eletrocardiograma contínuo durante todo o exercício e durante 5 minutos após a sua conclusão. Ao longo dos anos, a frequência cardíaca tornou-se um substituto para ventilação como medida da intensidade do exercício. No entanto, não é o ideal porque a frequência cardíaca durante o exercício não reflete a ventilação ou a taxa da perda respiratória de água ${ }^{50,75}$. Alguns pontos relevantes: em crianças, é preferível atingir $95 \%$ da frequência cardíaca máxima durante os últimos 4 minutos de exercício ${ }^{76}$, nas crianças mais pequenas, pode utilizar-se o $\mathrm{FEV}_{0,5}$ para diagnóstico da $\mathrm{AlE}^{77}$ e estas podem praticar exercício num ambiente divertido, por exemplo saltar num caste- 
lo insuflável ${ }^{78}$. Apesar de o PEF ter sido previamente usado com frequência, não é reprodutível como o FEV e não é atualmente recomendado ${ }^{79}$.

\section{Utilidade e limitações}

Uma provocação brônquica com exercício é clinicamente muito útil porque os sintomas frequentemente associados ao exercício vigoroso são semelhantes aos sintomas de asma e daí pode sobrevir um sobrediagnóstico. Importante referir que indivíduos saudáveis sem BIE podem ter estes sintomas e por outro lado aqueles com BIE podem não ter sintomas, pelo que poder identificar de forma objetiva a ocorrência de BIE é fundamental ${ }^{79}$. Do ponto de vista clínico, a prova de provocação com exercício evita tanto sobrediagnóstico como subdiagnóstico de BIE, comparativamente à utilização de apenas sintomas para o diagnóstico. Além disso, é relevante objetivar a ausência de BIE para algumas circunstâncias em que a sua existência limitaria o desempenho (órgãos de defesa, polícia, prática de mergulho, etc. $)^{79}$.

A Academia Americana de Alergia Asma e Imunologia (AAAAl) e o Colégio Americano de Alergia Asma e Imunologia (ACAAI) recomendam a prova de provocação brônquica com o exercício como o exame com maior utilidade para diagnóstico de BIE em indivíduos sem antecedentes de clínica de asma, com resultados normais de espirometria e sem resposta ao broncodilatador ${ }^{2}$.

As principais limitações para o diagnóstico de BIE com prova de exercício em laboratório residem em alguma dificuldade no controlo das condições ambientais (humidade e temperatura - conteúdo de água no ar $<10 \mathrm{mg}$ $\mathrm{H}_{2} \mathrm{O} / \mathrm{L}$, o que representa $50 \%$ de humidade aos $23^{\circ} \mathrm{C}^{80}$ ), mas principalmente na multiplicidade de protocolos usados, muitos dos quais são completamente inadequados para desencadear broncoconstrição ${ }^{79}$. Refira-se a título de exemplo o protocolo Bruce, amplamente usado pela cardiologia nas suas provas de esforço, que devido ao seu incremento lento frequentemente induz a libertação de mediadores broncodilatadores e por conseguinte um período refratário durante o qual não ocorrem sintomas brônquicos. Esta é causa frequente de resultados falsos-negativos. Pelo mesmo motivo, é fundamental instruir o examinando a evitar praticar exercício nas horas que antecedem esta prova de provocação.

Por outro lado, devido à variabilidade interexames, para excluir com segurança a possibilidade de BIE devem objetivar-se duas provocações negativas ${ }^{81}$.

Às vezes pode ser difícil objetivar BIE através da prova de provocação com exercício clássica, realizada em ambiente mais controlado e diferente da prática de exercício habitual. Nestas situações pode ser útil, sobretudo se o desporto praticado tem características muito diferentes da corrida ou da bicicleta (uma vez que as provas de exercício em laboratório utilizam tapete ou cicloergómetro), realizar a prova no "terreno", ou seja, onde habitualmente se realiza a prática desportiva que induz sintomas, ou num local com condições e características semelhantes (ex. piscinas ou pavilhões gimnodesportivos), com medições seriadas da função respiratória antes e após a cessação do esforço. Tem sido alegado que uma provocação com exercício em campo teria maior probabilidade de reproduzir os sintomas ${ }^{82}$, mas isso não foi confirmado por outros estudos ${ }^{83,84}$. Além disso, uma provocação com exercício em campo pode ser inconveniente, tanto por questões logísticas quanto para estandardização ${ }^{39}$.

\section{Hiperventilação voluntária eucápnica}

Tal como referido, é fundamental que o protocolo usado no laboratório seja suficiente para desencadear os sintomas de BIE. Nem sempre é possível assegurar que todos os indivíduos sob investigação consigam atingir o nível de ventilação necessário e manter exercício em tapete ou cicloergómetro numa intensidade suficiente e pelo tempo necessário para provocar broncoconstrição. No sentido de colmatar esta limitação, que ocorre sobretudo em atletas e outros indivíduos fisicamente bem condicionados, foi desenvolvido um teste alternativo que consiste em atingir elevados níveis de ventilação. $\mathrm{O}$ racional para o seu desenvolvimento remonta aos anos 70 , 
quando estudos em crianças e adultos demonstraram que o determinante major para a ocorrência e sobretudo para a gravidade da BIE não era o exercício em si, mas a taxa de ventilação atingida e sustentada durante a prática de exercício ${ }^{85-87}$. Nos anos 80 desenvolveram-se alguns protocolos usando hiperpneia voluntária de ar seco com adição de dióxido de carbono $\left(\mathrm{CO}_{2}\right)^{88,89}$, mas tinham vários requisitos técnicos de forma a manterem estáveis os níveis de $\mathrm{CO}_{2}$ e rapidamente se revelaram pouco atrativos para a prática diária em laboratórios clínicos. Desenvolveu-se posteriormente um sistema simplificado usando um nível constante de $\mathrm{CO}_{2}$ numa mistura de gás inalada à temperatura ambiente ${ }^{90,91}$, com o objetivo de identificar BIE em recrutas militares - foi designado por hiperventilação voluntária eucápnica (HVE). Requeria uma fonte de gás comprimido à temperatura ambiente contendo $21 \%$ de $\mathrm{O}_{2}, 4,9-5 \% \mathrm{CO}_{2}$ e o restante de $\mathrm{N}_{2}{ }^{28,92,93}$. Por ter sido desenvolvido para recrutas fisicamente bem condicionados, originalmente sugeria atingir-se um nível de ventilação elevado de ventilação para diagnóstico de BIE - 30xFEV, equivalente a $85 \%$ da MVV, sustentado por 6 minutos.

Nos últimos anos, foram disponibilizados comercialmente alguns sistemas capazes de monitorizar e ajustar o $\mathrm{CO}_{2}$ para manter a eucapnia durante a hiperpneia até 220 L/min, com um ecrã (Eucapsys ${ }^{\circledR}$, SMTEC, Suíça). Isso facilitou o diagnóstico de BIE em atletas no laboratório clínico porque a ventilação não se limita a $105 \mathrm{~L} / \mathrm{min}$, como era necessário quando era inalado um nível constante de $\mathrm{CO}_{2}{ }^{50}$. Outros dispositivos também foram desenvolvidos na Suécia (Ailos Medicinsk Teknik ${ }^{\circledR}$, Karlstad) e posteriormente nos EUA (Rosenthal Hyperventilometer ${ }^{\circledR}$ ).

A duração da ventilação e as condições do ar inspirado podem ser alteradas se necessário para mimetizar as condições sob as quais o exercício é realizado, ou seja, ar frio, etc. No caso dos atletas, alguns autores advogam que $\circ$ teste de escolha nestes casos, pela sua sensibilidade, deve ser a prova de hiperventilação com ar seco; no caso de se tratar de um desporto de inverno, esta prova de hiperventilação deverá ser efetuada com ar frio.

\section{Utilidade e limitações}

A HVE é um teste muito útil para identificar BIE em atletas com função pulmonar normal ${ }^{94,95}$. Para esta finalidade o protocolo padrão de 6 minutos com ventilação-alvo de 30xFEV, é mais sensível do que a provocação com exercício; a frequência de resultados falso-negativos é baixa ${ }^{82,96}$. Este protocolo padronizado não é recomendado em asmáticos sintomáticos ou não controlados ou cuja função pulmonar não é normal, sendo aconselhável ventilação mais baixa $-21 \times \mathrm{FEV}_{1}$, equivalente a $60 \%$ da MVV93,97.

Há vantagens em usar a HVE comparativamente a uma prova com exercício - I) requer menos equipamentos e menos pessoal; 2) é mais silenciosa; 3) é menos stressante do que o exercício para um nível equivalente de ventilação; 4) a duração é menor porque a ventilação-alvo é atingida em segundos e não em minutos, como ocorre com o exercício ${ }^{75}$; 5 ) a maior vantagem é que a ventilação-alvo excede a ventilação máxima possível durante o exercício, pelo que os testes falso-negativos são improváveis.

A principal limitação na utilização da HVE é a necessidade de manter a eucapnia numa ampla gama de ventilação. $O F E V_{\text {, deve ser }} \geq 1,5 \mathrm{~L}$ e a ventilação precisa de 40-105 L/min para usar a mistura gasosa preparada. Se o $\mathrm{FEV}$, for inferior ou a ventilação estiver fora dos limites, então $\circ \mathrm{CO}_{2}$ na expiração precisa de ser monitorizado para eucapnia. Tal é importante porque a hipocapnia é um estímulo broncoconstritor em si e, por outro lado, a hipercapnia induz acidose.

Outra limitação é o potencial para induzir queda rápida e grave do $\mathrm{FEV}_{1}(>30 \%)$ após a prova ${ }^{98}$, o que pode ser um risco. Há também quem reporte que é desconfortável para executar ${ }^{99}$. Por outro lado, o dispositivo é bastante dispendioso.

\section{Inalação de soluto hipertónico}

A ideia de realizar uma prova de provocação com um aerossol de solução salina hipertónica remonta ao início dos anos 80 , quando se descreveram pela primeira vez 
os seus efeitos broncoconstritores ${ }^{100}$. O racional reside na hipótese osmótica para a etiopatogenia da BIE, já referida.

Nos primeiros estudos, a prova com a solução salina hipertónica começou com uma exposição de 60 segundos e continuava até uma queda de $20 \%$ no FEV, ou uma dose cumulativa de $30 \mathrm{~mL}$. Muitos doentes asmáticos eram bastante sensíveis a estes aerossois e o tempo de exposição inicial foi posteriormente reduzido para 30 segundos e a dose máxima para 15,5mL. A investigação prosseguiu, com diferentes concentrações de solução salina, e demonstrou-se que era a taxa de osmolaridade que era importante e por isso foi aumentada a concentração de $3,6 \%$ (concentração de água do mar) para $4,5 \%{ }^{50}$. 0 aumento para $4,5 \%$ de solução salina reduziu o tempo de exposição e o número de resultados falso-negativos e tornou o teste prático para uso clínico ${ }^{101}$. A solução salina de $4,5 \%$ é inicialmente administrada 30 segundos e depois I, 2, 4 e 8 minutos, com espirometria intercalada. $O$ limiar de positividade fixou-se na queda $\mathrm{FEV}_{1} \geq 15 \%$. Crianças com esta prova positiva pareciam ter um risco 5 vezes superior de apresentar AIE ${ }^{102}$. Posteriormente os resultados foram comparados com provas com exercício e HVE e a sensibilidade foi concordante na maioria dos $\operatorname{casos}^{101,103}$.

\section{Utilidade e limitações}

As grandes vantagens deste tipo de provocação são o material usado e o tempo despendido. Por exemplo, para a prova com exercício ou EVH são necessários, além do espirómetro, equipamentos dispendiosos que ocupam bastante espaço e que requerem pessoal treinado em utilizá-los. Neste caso, apenas são necessários o nebulizador ultrassónico e a solução salina hipertónica. Acresce a vantagem de se poder aproveitar a técnica também para realizar esputo induzido.

É uma prova desagradável para o examinando devido à excessiva produção de saliva e para o examinador devido à elevada concentração de partículas no ambiente do laboratório, o que limita a sua utilização dos pontos de vista técnico e de higiene ${ }^{50}$. Além disso, o tamanho das partículas de aerossol pode alterar-se ao longo do tempo de vida do cristal piezoelétrico do nebulizador, o que influencia o resultado.

Embora a prova de provocação com soluto hipertónico não seja correntemente muito utilizada, há evidência científica forte de que a resposta a esta prova é similar a outras provas indiretas, como exercício ou HVE para diagnóstico de $\mathrm{BIE}^{34,102-106}$. A resposta nesta prova correlaciona-se com a infiltração mastocitária nas vias aéreas e eosinófilos no esputo ${ }^{107,108}$; a solução hipertónica conduz à libertação de neuropéptidos que estão envolvidos na ocorrência de broncoconstrição ${ }^{109}$.

\section{Prova com manitol}

Mantendo por base a teoria osmótica, mas com o objetivo de simplificar a prova com soluto hipertónico e obviar as suas desvantagens, surgiu nos anos 90 a inalação de pó seco de manitol. Este é encapsulado nas doses de 5, 10, 20, 40 mg; para uma prova completa são administradas as doses referidas e ainda 80,160 e $320 \mathrm{mg}$, usando múltiplas cápsulas de $40 \mathrm{mg}$. $\mathrm{FEV}$, é avaliado 60 segundos após cada dose, e a prova progride até à inalação de $635 \mathrm{mg}$ ou até se objetivar uma queda no FEVI $\geq 15 \%$, que determina a positividade.

O manitol encontra-se comercializado em kits com cápsulas e inalador (Aridol ${ }^{\mathrm{TM}}$ ou Osmohale ${ }^{\mathrm{TM}}$ Pharmaxis Ltd, Frenchs Forest, NSW, Austrália) nos vários continentes, mas não em todos os países.

\section{Utilidade e limitações}

As principais vantagens da prova com manitol são o facto de a sua natureza incremental limitar a ocorrência de broncoespasmos graves, como os que podem ocorrer com exercício ou HVE, e o equipamento mínimo que requer - apenas um relógio, além do espirómetro comum a todas as provas. A questão do tempo é fundamental porque a resposta ao manitol depende do aumento progressivo do gradiente osmótico. Para isso, é necessário inalar cada dose de manitol o mais rapida- 
mente possível após a última dose. A sensibilidade do manitol para identificar BIE é superior quando o tempo total da prova é inferior a 35 minutos $^{36}$, e para uma utilização ótima este limiar de tempo para atingir os $635 \mathrm{mg}$ não deve mesmo ser ultrapassado. Desde que está registado, vários estudos demonstraram a sua utilidade para diagnosticar $\mathrm{BIE}^{110-112}$ e encontra-se recomendado em vários consensos ${ }^{1,2,105}$.

Uma das principais limitações à sua utilização é a tosse que induz no examinando. Outros efeitos adversos no dia da prova incluem odinofagia ( $2,6 \%$ dos casos), irritação faríngea $(\mathrm{I}, \mathrm{I} \%)$ e náuseas $(\mathrm{I}, \mathrm{I} \%)$.

\section{DETERMINAÇÃO DA INFLAMAÇÃO BRÔNQUICA}

A medição da fração exalada de óxido nítrico é um método não invasivo e válido para a avaliação da inflamação brônquica. Consiste em determinar, no ar que é exalado dos pulmões, a concentração de óxido nítrico (fórmula química: NO), que está presente; menos de $1 \%$ do ar exalado dos pulmões humanos corresponde a uma miríade de gases, com concentrações muito baixas, que resultam maioritariamente da atividade bioquímica que ocorre nas várias camadas dos brônquios, podendo também representar atividade sistémica. A FeNO é primariamente um marcador de inflamação brônquica mediada por IL-4 e IL-I3 ${ }^{1 / 3}$. A sua interpretação é geralmente feita através da utilização de valores de corte fixos (utilizando a unidade partes por bilião), conforme sugerido pela American Thoracic Society ${ }^{114}$, embora recentemente tenha aumentado o desenvolvimento de equações de referência que incorporem os fatores específicos de cada indivíduo, como sexo, idade, altura e hábitos tabágicos ${ }^{115}$.

Valores aumentados de $\mathrm{FeNO}$ estão associados a $\mathrm{BIE}$ em crianças com asma atópica, independentemente de outros marcadores de gravidade de asma ou dose de medicação. É sugerido que a FeNO possa ser utili- zada como ferramenta de rastreio de BIE neste grupo etário. A BIE correlaciona-se ainda com a FENO e a prova de provocação brônquica com manitol. Considerando que a determinação da FeNO é um exame mais rápido e seguro do que a provocação brônquica com manitol, é sugerida a sua utilização também como ferramenta diagnóstica.

Outro método não invasivo para avaliação da inflamação brônquica é a análise do esputo induzido. Não é uma prática clínica habitual, tendo sido utilizado maioritariamente em estudos de investigação para determinar a etiopatogenia da BIE. Requer pessoal treinado na indução do esputo, bem como no processamento e análise das amostras. Pode ser realizado com segurança após uma prova de broncoprovocação com exercício em asmáticos com BIE ${ }^{116}$, mas não é realizado por rotina, uma vez que as guidelines não preveem ajustes terapêuticos conforme os seus resultados.

\section{CONTRAINDICAÇÕES E PRECAUÇÕES}

Como a resposta das vias aéreas depende da intensidade do esforço e de variáveis ambientais, como temperatura, humidade do ar e hora do dia ${ }^{117,118}$, é crucial conhecer as condições sob as quais a prova de provocação brônquica foi realizada para se concluir uma adequada interpretação dos seus resultados ${ }^{119}$.

Ao contrário das provas incrementais, a HVE ou a prova com exercício podem induzir broncoespasmo rápido e grave, pelo que é imperativo que o laboratório disponha do equipamento e pessoal habilitado a lidar com a situação. Devido a este risco, não se recomenda a sua realização se $\mathrm{FEV}$, basal $\leq 75 \%$ do previsto e saturação de $\mathrm{O}_{2} \leq 94 \%{ }^{34}$. Outras contraindicações incluem doença cardiovascular significativa, gravidez, epilepsia, etc ${ }^{34}$. Vários fármacos, alimentos e circunstâncias influenciam a reatividade brônquica, pelo que deve ser fornecida previamente uma lista com os cuidados e evicções, de acordo com o publicado ${ }^{34}$. 


\section{CONSIDERAÇÕES FINAIS}

A BIE é frequentemente subdiagnosticada e, consequentemente, subtratada, devendo provavelmente ser avaliada de um modo sistemático nos desportistas, uma vez que os sintomas não são um bom preditor de patologia. Por outro lado, na população geral, a semelhança dos sintomas de BIE com asma pode induzir um sobrediagnóstico com consequente terapêutica desnecessária. Na Figura 4 propõe-se um algoritmo de diagnóstico.

Importa reforçar que nenhum dos testes atualmente disponíveis isolado permite identificar todos os indivíduos com BIE. Existem variações na resposta das vias aéreas de umas provas comparadas com outras e até com a mesma prova, pelo que conhecer as propriedades de cada exame é fundamental para organizar o estudo da situação clínica. A HVE produz um estímulo broncoconstritor mais potente e deve ser considerada como alternativa quando a prova de exercício é negativa.

Quando o objetivo é avaliar a presença de BIE em doente com asma conhecida, iniciar por uma prova incremental, como é o caso do manitol, é preferível por razões de segurança. Se esta for negativa e a suspeita

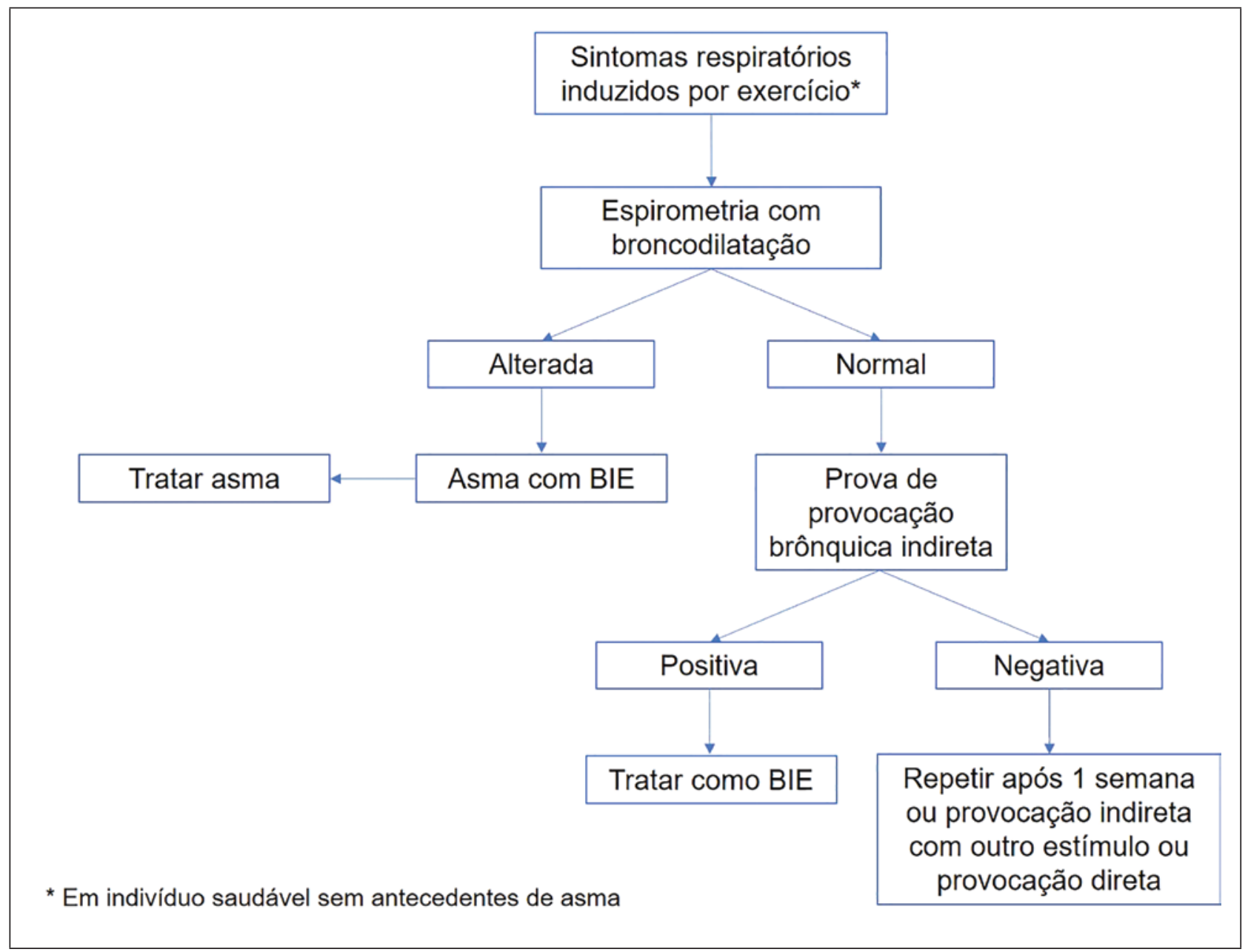

Figura 4. Fluxograma de investigação de suspeita de broncoconstrição induzida por exercício (BIE) 
clínica forte, então deverá ser considerada uma prova adicional com outro estímulo.

Para atletas de alta competição, as provas de broncoprovocação aceites para diagnóstico de BIE são exercício, HVE, solutos hiperosmolares, manitol e metacolina. Provas de provocação brônquica com outros estímulos, como histamina ou monofosfato de adenosina, não são aceites pela Comissão Médica do Comité Olímpico Internacional. Importa frisar que com uma correta avaliação e tratamento a BIE não deverá ser um constrangimento para o desempenho dos jovens que praticam desporto de forma recreativa ou de alta competição.

\section{Conflito de interesses}

Os autores declaram que não existem conflitos de interesse.

\section{Contacto:}

Mariana Couto

marianafercouto@gmail.com

\section{REFERÊNCIAS}

I Global Initiative for Asthma. GINA 2018 [Available from: http:/ ginasthma.org/.

2. Weiler JM, Brannan JD, Randolph CC, Hallstrand TS, Parsons J, Silvers W, et al. Exercise-induced bronchoconstriction update-2016. J Allergy Clin Immunol 2016;138:1292-5.e36.

3. Couto M, Kurowski M, Moreira A, Bullens DMA, Carlsen KH, Delgado L, et al. Mechanisms of exercise-induced bronchoconstriction in athletes: Current perspectives and future challenges. Allergy 2018;73:8-16.

4. Weiler JM, Bonini S, Coifman R, Craig T, Delgado L, Capao-Filipe M, et al. American Academy of Allergy, Asthma \& Immunology Work Group report: exercise-induced asthma. J Allergy Clin Immunol 2007; I19:1349-58.

5. Caillaud D, Horo K, Baiz N, Banerjee S, Charpin D, Lavaud F, et al. Exercise-induced bronchospasm related to different phenotypes of rhinitis without asthma in primary schoolchildren: the French Six Cities Study. Clin Exp Allergy 2014;44:858-66.

6. Aggarwal B, Mulgirigama A, Berend N. Exercise-induced bronchoconstriction: prevalence, pathophysiology, patient impact, diagnosis and management. NPJ Prim Care Respir Med 2018; 28:31.

7. Anthracopoulos MB, Fouzas S, Papadopoulos M, Antonogeorgos G, Papadimitriou A, Panagiotakos DB, et al. Physical activity and exercise-induced bronchoconstriction in Greek schoolchildren. Pediatr Pulmonol 2012;47:1080-7.

8. Burr ML, Wat D, Evans C, Dunstan FD, Doull IJ. Asthma prevalence in 1973, 1988 and 2003. Thorax 2006;61:296-9.

9. Cichalewski L, Majak P, Jerzynska J, Stelmach W, Kaczmarek A, Malewska K, et al. Prevalence of exercise-induced cough in schoolchildren: a pilot study. Allergy Asthma Proc 2015;36:65-9.

10. Johansson H, Norlander K, Berglund L, Janson C, Malinovschi A, Nordvall L, et al. Prevalence of exercise-induced bronchoconstriction and exercise-induced laryngeal obstruction in a general adolescent population. Thorax 2015;70:57-63.

II. Lin LL, Huang SJ, Ou LS, Yao TC, Tsao KC, Yeh KW, et al. Exercise-induced bronchoconstriction in children with asthma: An observational cohort study. J Microbiol Immunol Infect 2019;52:47I-9.

12. Couto M, Stang J, Horta L, Stensrud T, Severo M, Mowinckel P, et al. Two distinct phenotypes of asthma in elite athletes identified by latent class analysis. J Asthma 2015;52:897-904.

13. Miller MR, Hankinson J, Brusasco V, Burgos F, Casaburi R, Coates A, et al. Standardisation of spirometry. Eur Respir J 2005;26:319-38.

14. Quanjer PH, Stanojevic S, Cole TJ, Baur X, Hall GL, Culver BH, et al. Multi-ethnic reference values for spirometry for the 3-95-yr age range: the global lung function 2012 equations. Eur Respir J 2012;40:1324-43.

15. Bonini M, Lapucci G, Petrelli G, Todaro A, Pamich T, Rasi G, et al. Predictive value of allergy and pulmonary function tests for the diagnosis of asthma in elite athletes. Allergy 2007;62:1 166-70.

16. Pellegrino R, Viegi G, Brusasco V, Crapo RO, Burgos F, Casaburi $R$, et al. Interpretative strategies for lung function tests. Eur Respir J 2005;26:948-68.

17. Brannan JD, Porsbjerg C. Testing for Exercise-Induced Bronchoconstriction. ImmunolAllergy Clin North Am 2018;38:215-29.

18. Jones RS, Buston MH, Wharton MJ. The effect of exercise on ventilatory function in the child with asthma. $\mathrm{Br} J \mathrm{Dis}$ Chest 1962;56:78-86.

19. Jones RS, Wharton MJ, Buston MH. The place of physical exercise and bronchodilator drugs in the assessment of the asthmatic child. Arch Dis Child 1963;38:539-45.

20. Cox JS. Disodium cromoglycate (FPL 670) ('Intal'): a specific inhibitor of reaginic antibody-antigen mechanisms. Nature 1967;216(5122):1328-9.

21. Altounyan REC. Inhibition of experimental asthma by a new compound, disodium cromoglycate. Acta Allerg 1967;22:487.

22. Pierson WE, Bierman CW, Stamm SJ. Cycloergometer-induced bronchospasm. J Allergy 1969;43:136-44. 
23. Godfrey S, Silverman M, Anderson SD. Problems of interpreting exercise-induced asthma. J Allergy Clin Immunol 1973;52:199-209.

24. Cropp GJ. Grading, time course, and incidence of exercise-induced airway obstruction and hyperinflation in asthmatic children. Pediatrics 1975;56(5 pt-2 suppl):868-79.

25. Cropp GJ. Relative sensitivity of different pulmonary function tests in the evaluation of exercise-induced asthma. Pediatrics 1975;56(5 pt-2 suppl):860-7.

26. Joos GF, Kips JC, Pauwels RA. Direct and indirect bronchial responsiveness. Respir Med 1993;87 Suppl B:31-6.

27. Van Schoor J, Joos GF, Pauwels RA. Indirect bronchial hyperresponsiveness in asthma: mechanisms, pharmacology and implications for clinical research. Eur Respir J 2000;16:514-33.

28. Anderson SD, Brannan JD. Methods for "indirect" challenge tests including exercise, eucapnic voluntary hyperpnea, and hypertonic aerosols. Clin Rev Allergy Immunol 2003;24:27-54.

29. de Meer G, Marks GB, Postma DS. Direct or indirect stimuli for bronchial challenge testing: what is the relevance for asthma epidemiology? Clin Exp Allergy 2004;34:9-16.

30. Moreira A, Delgado L, Carlsen KH. Exercise-induced asthma: why is it so frequent in Olympic athletes? Expert Rev Respir Med 2011;5:I-3.

31. Parsons JP, Mastronarde JG. Exercise-induced bronchoconstriction in athletes. Chest 2005;128:3966-74.

32. Fitch KD, Sue-Chu M, Anderson SD, Boulet LP, Hancox RJ, McKenzie DC, et al. Asthma and the elite athlete: summary of the International Olympic Committee's consensus conference, Lausanne, Switzerland, January 22-24, 2008. J Allergy Clin Immunol 2008;122:254-60.el-7.

33. Coates AL, Wanger J, Cockcroft DW, Culver BH, Diamant Z, Gauvreau G, et al. ERS technical standard on bronchial challenge testing: general considerations and performance of methacholine challenge tests. Eur Respir J 2017;49(5).

34. Hallstrand TS, Leuppi JD, Joos G, Hall GL, Carlsen KH, Kaminsky DA, et al. ERS technical standard on bronchial challenge testing: pathophysiology and methodology of indirect airway challenge testing. Eur Respir J 2018;52(5).

35. Joos GF, O'Connor B, Anderson SD, Chung F, Cockcroft DW, Dahlen B, et al. Indirect airway challenges. Eur Respir J 2003;21:1050-68.

36. Anderson SD, Charlton B, Weiler JM, Nichols S, Spector SL, Pearlman DS. Comparison of mannitol and methacholine to predict exercise-induced bronchoconstriction and a clinical diagnosis of asthma. Respir Res 2009;10:4.

37. Cockcroft DW, Davis BE. Diagnostic and therapeutic value of airway challenges in asthma. Curr Allergy Asthma Resp 2009;9:247-53.

38. Holzer K, Anderson SD, Douglass J. Exercise in elite summer athletes: Challenges for diagnosis. J Allergy Clin Immunol 2002;110:374-80.
39. Del Giacco SR, Firinu D, Bjermer L, Carlsen KH. Exercise and asthma: an overview. Eur Clin Respir J 2015;2:27984.

40. Brannan JD, Gulliksson M, Anderson SD, Chew N, Kumlin M. Evidence of mast cell activation and leukotriene release after mannitol inhalation. Eur Respir J 2003;22:49I-6.

4I. O'Sullivan S, Roquet A, Dahlen B, Larsen F, Eklund A, Kumlin M, et al. Evidence for mast cell activation during exercise-induced bronchoconstriction. Eur Respir J 1998;12:345-50.

42. Worldwide variation in prevalence of symptoms of asthma, allergic rhinoconjunctivitis, and atopic eczema: ISAAC. The International Study of Asthma and Allergies in Childhood (ISAAC) Steering Committee. Lancet 1998;351:1225-32.

43. Rodwell LT, Anderson SD, Seale JP. Inhaled steroids modify bronchial responses to hyperosmolar saline. Eur Respir J 1992;5:953-62.

44. Pauwels R, Joos G, Van der Straeten M. Bronchial hyperresponsiveness is not bronchial hyperresponsiveness is not bronchial asthma. Clin Allergy 1988;18:317-21.

45. Eggleston PA, Bierman CW, Pierson WE, Stamm SJ, Van Arsdel $\mathrm{PP}, \mathrm{Jr}$. A double blind trial of the effect of cromolyn sodium on exercise-induced bronchospasm. J Allergy Clin Immunol 1972;50:57-63.

46. Fitch KD, Morton AR. Specificity of exercise in exercise-induced asthma. Br Med J 1971;4(5787):577-8I.

47. Anderson SD, Connolly NM, Godfrey S. Comparison of bronchoconstriction induced by cycling and running. Thorax 1971;26:396-40I.

48. Silverman M, Anderson SD. Standardization of exercise tests in asthmatic children. Clin Exp Allergy 1972;47:882-9.

49. Wright BM, Mc KC. Maximum forced expiratory flow rate as a measure of ventilatory capacity: with a description of a new portable instrument for measuring it. Br Med J 1959;2(5159):1041-6.

50. Anderson SD. 'Indirect' challenges from science to clinical practice. Eur Clin Respir J 2016;3:31096.

5I. Eggleston PA. The cycloergometer as a system for studying exercise-induced asthma. Pediatrics 1975;56(5 pt-2 suppl):899-903.

52. Bierman EW, Kawabori I, Pierson WE. Incidence of exercise-induced asthma in children. Pediatrics 1975;56(5 pt-2 suppl):847-50.

53. Kattan M, Keens TG, Mellis CM, Levison H. The response to exercise in normal and asthmatic children. J Pediatr 1978;92:718-2I.

54. Anderson SD, Silverman M, Konig P, Godfrey S. Exercise-induced asthma. Br J Dis Chest 1975;69:1-39.

55. Eggleston PA, Rosenthal RR, Anderson SA, Anderton R, Bierman $\mathrm{CW}$, Bleecker ER, et al. Guidelines for the methodology of exercise challenge testing of asthmatics. Study Group on Exercise Challenge, Bronchoprovocation Committee, American Academy of Allergy. J Allergy Clin Immunol 1979;64(6 pt 2):642-5.

56. Eggleston PA. Laboratory evaluation of exercise-induced asthma: methodologic considerations. J Allergy Clin Immunol 1979;64(6 pt 2):604-8. 
57. Pierson WE, Bierman CW. Free running test for exercise-induced bronchospasm. Pediatrics 1975;56(5 pt-2 suppl):890-2.

58. Fitch KD, Morton AR, Blanksby BA. Effects of swimming training on children with asthma. Clin Exp Allergy 1976;51:190-4.

59. Bar-Or O, Neuman I, Dotan R. Effects of dry and humid climates on exercise-induced asthma in children and preadolescents. J Allergy Clin Immunol 1977;60:163-8.

60. Chen WY, Horton DJ. Heat and water loss from the airways and exercise-induced asthma. Respiration 1977;34:305-13.

6I. Strauss RH, McFadden ER Jr, Ingram RH Jr, Deal EC Jr, Jaeger JJ. Influence of heat and humidity on the airway obstruction induced by exercise in asthma. J Clin Invest 1978;61:433-40.

62. Anderson SD, Daviskas E, Schoeffel RE, Unger SF. Prevention of severe exercise-induced asthma with hot humid air. Lancet 1979;2(8I43):629.

63. Strauss RH, McFadden ER, Jr., Ingram RH, Jr., Jaeger JJ. Enhancement of exercise-induced asthma by cold air. N Engl J Med 1977;297:743-7.

64. Deal EC, Jr., McFadden ER, Jr., Ingram RH, Jr., Strauss RH, Jaeger JJ. Role of respiratory heat exchange in production of exercise-induced asthma. J Appl Physiol Respir Environ Exerc Physiol 1979;46:467-75.

65. Deal EC, Jr., McFadden ER, Jr., Ingram RH, Jr., Jaeger JJ. Hyperpnea and heat flux: initial reaction sequence in exercise-induced asthma.J Appl Physiol Respir Environ Exerc Physioll 979;46:476-83.

66. Anderson SD, Schoeffel RE, Follet R, Perry CP, Daviskas E, Kendall $M$. Sensitivity to heat and water loss at rest and during exercise in asthmatic patients. Eur J Respir Dis 1982;63:459-71.

67. Schoeffel RE, Anderson SD, Altounyan RE. Bronchial hyperreactivity in response to inhalation of ultrasonically nebulised solutions of distilled water and saline. $\mathrm{Br}$ Med J (Clin Res Ed) 1981;283(6302):I285-7.

68. Aitken ML, Marini JJ. Effect of heat delivery and extraction on airway conductance in normal and in asthmatic subjects. Am Rev Respir Dis 1985;131:357-61.

69. Hahn A, Anderson SD, Morton AR, Black JL, Fitch KD. A reinterpretation of the effect of temperature and water content of the inspired air in exercise-induced asthma. Am Rev Respir Dis 1984;130:575-9.

70. Anderson SD. Is there a unifying hypothesis for exercise-induced asthma? J Allergy Clin Immunol 1984;73(5 Pt 2):660-5.

7I. Anderson SD, Schoeffel RE, Black JL, Daviskas E. Airway cooling as the stimulus to exercise-induced asthma--a re-evaluation. Eur J Respir Dis 1985;67:20-30.

72. McFadden ER Jr, Lenner KA, Strohl KP. Postexertional airway rewarming and thermally induced asthma. New insights into pathophysiology and possible pathogenesis. J Clin Invest 1986;78:18-25.

73. Anderson SD, Holzer K. Exercise-induced asthma: is it the right diagnosis in elite athletes? J Allergy Clin Immunol 2000;106:419-28.
74. Smith CM, Anderson SD, Walsh S, McElrea MS. An investigation of the effects of heat and water exchange in the recovery period after exercise in children with asthma. Am Rev Respir Dis 1989;140:598-605.

75. Anderson SD, Lambert S, Brannan JD, Wood RJ, Koskela H, Morton AR, et al. Laboratory protocol for exercise asthma to evaluate salbutamol given by two devices. Med Sci Sports Exerc 2001;33:893-900.

76. Carlsen KH, Engh G, Mork M. Exercise-induced bronchoconstriction depends on exercise load. Respir Med 2000;94:750-5.

77. Vilozni D, Bentur L, Efrati O, Barak A, Szeinberg A, Shoseyov D, et al. Exercise challenge test in 3- to 6-year-old asthmatic children. Chest 2007;132:497-503.

78. van Leeuwen JC, Driessen JM, de Jongh FH, Anderson SD, Thio BJ. Measuring breakthrough exercise-induced bronchoconstriction in young asthmatic children using a jumping castle. J Allergy Clin Immunol 2013;131:1427-9.e5.

79. Anderson S. Bronchial challenge tests: usefulness, availability and limitations. Breath. 2011;8:53-60.

80. Haby MM, Anderson SD, PeatJK, Mellis CM, Toelle BG, Woolcock AJ. An exercise challenge protocol for epidemiological studies of asthma in children: comparison with histamine challenge. Eur Respir J 1994;7:43-9.

8I. Anderson SD, Pearlman DS, Rundell KW, Perry CP, Boushey H, Sorkness CA, et al. Reproducibility of the airway response to an exercise protocol standardized for intensity, duration, and inspired air conditions, in subjects with symptoms suggestive of asthma. Respir Res 2010;11:120.

82. Rundell KW, Wilber RL, Szmedra L, Jenkinson DM, Mayers LB, Im $J$. Exercise-induced asthma screening of elite athletes: field versus laboratory exercise challenge. Med Sci Sports Exerc 2000;32:309-16.

83. Dickinson JW, Whyte GP, McConnell AK, Harries MG. Screening elite winter athletes for exercise induced asthma: a comparison of three challenge methods. Br J Sports Med 2006;40:179-82.

84. Stensrud T, Mykland KV, Gabrielsen K, Carlsen KH. Bronchial hyperresponsiveness in skiers: field test versus methacholine provocation? Med Sci Sports Exerc 2007;39:1681-6.

85. Chan-Yeung MM, Vyas MN, Grzybowski S. Exercise-induced asthma. Am Rev Respir Dis1971;104:915-23.

86. Zeballos RJ, Shturman-Ellstein R, McNally JF, Jr., Hirsch JE, Souhrada JF. The role of hyperventilation in exercise-induced bronchoconstriction. Am Rev Respir Dis 1978; I18(5):877-84.

87. Kilham H, Tooley M, Silverman M. Running, walking, and hyperventilation causing asthma in children. Thorax 1979;34:582-6.

88. Kivity S, Souhrada JF, Melzer E. A dose-response-like relationship between minute ventilation and exercise-induced bronchoconstriction in young asthmatic patients. Eur J Respir Dis 1980;61:342-6.

89. Kivity S, Souhrada JF. Hyperpnea: the common stimulus for bronchospasm in asthma during exercise and voluntary isocapnic hyperpnea. Respiration 1980;40:169-77. 


\section{AVALIAÇÃO OBJETIVA NO DIAGNÓSTICO \\ DE BRONCOCONSTRIÇÃO INDUZIDA PELO EXERCÍCIO I ARTIGO DE REVISÃO}

90. Rosenthal RR. Simplified eucapnic voluntary hyperventilation challenge. J Allergy Clin Immunol 1984;73(5 Pt 2):676-9.

91. Phillips YY, Jaeger JJ, Laube BL, Rosenthal RR. Eucapnic voluntary hyperventilation of compressed gas mixture. A simple system for bronchial challenge by respiratory heat loss. Am Rev Respir Dis 1985;|31:31-5.

92. Argyros GJ, Roach JM, Hurwitz KM, Eliasson AH, Phillips YY. Eucapnic voluntary hyperventilation as a bronchoprovocation technique: development of a standarized dosing schedule in asthmatics. Chest 1996;109:1520-4.

93. Anderson SD, Argyros GJ, Magnussen H, Holzer K. Provocation by eucapnic voluntary hyperpnoea to identify exercise induced bronchoconstriction. Br J Sports Med 200I;35:344-7.

94. Anderson SD, Fitch K, Perry CP, Sue-Chu M, Crapo R, McKenzie $D$, et al. Responses to bronchial challenge submitted for approval to use inhaled beta2-agonists before an event at the 2002 Winter Olympics. J Allergy Clin Immunol 2003;1 II:45-50.

95. Dickinson J, McConnell A, Whyte G. Diagnosis of exercise-induced bronchoconstriction: eucapnic voluntary hyperpnoea challenges identify previously undiagnosed elite athletes with exercise-induced bronchoconstriction. Br J Sports Med 201।;45:II26-3I.

96. Mannix ET, Manfredi F, Farber MO. A comparison of two challenge tests for identifying exercise-induced bronchospasm in figure skaters. Chest 1999;115:649-53.

97. Brummel NE, Mastronarde JG, Rittinger D, Philips G, Parsons JP. The clinical utility of eucapnic voluntary hyperventilation testing for the diagnosis of exercise-induced bronchospasm. J Asthma. 2009;46:683-6.

98. Holzer K, Anderson SD, Chan HK, Douglass J. Mannitol as a challenge test to identify exercise-induced bronchoconstriction in elite athletes. Am J Respir Crit Care Med 2003;167:534-7.

99. Stadelmann K, Stensrud T, Carlsen KH. Respiratory symptoms and bronchial responsiveness in competitive swimmers. Med Sci Sports Exerc 2011;43:375-8I.

100. Allegra L, Bianco S. Non-specific broncho-reactivity obtained with an ultrasonic aerosol of distilled water. Eur J Respir Dis Suppl 1980;106:41-9.

10I. Smith CM, Anderson SD. Inhalation provocation tests using nonisotonic aerosols. J Allergy Clin Immunol 1989;84(5 Pt I):78I-90.

102. Riedler J, Reade T, Dalton M, Holst DI, Robertson CF. Hypertonic saline challenge in an epidemiological survey of asthma in children. Am J Respir Crit Care Med 1994;150:1632-9.

103. Smith CM, Anderson SD. Inhalational challenge using hypertonic saline in asthmatic subjects: a comparison with responses to hyperpnoea, methacholine and water. Eur Respir J 1990;3:144-5I.

104. Choi IS, Chung SW, Koh YI, Sim MK, Hong SN, Moon JS. Airway hyperresponsiveness to hypertonic saline as a predictive index of exercise-induced bronchoconstriction. Korean J Intern Med 2005;20:284-9.
105. Parsons JP, Hallstrand TS, Mastronarde JG, Kaminsky DA, Rundell KW, Hull JH, et al. An official American Thoracic Society clinical practice guideline: exercise-induced bronchoconstriction. Am J Respir Crit Care Med 2013;187:1016-27.

106. Smith CM, Anderson SD. A comparison between the airway response to isocapnic hyperventilation and hypertonic saline in subjects with asthma. Eur Respir J 1989;2:36-43.

107. Porsbjerg C, Brannan JD, Anderson SD, Backer V. Relationship between airway responsiveness to mannitol and to methacholine and markers of airway inflammation, peak flow variability and quality of life in asthma patients. Clin Exp Allergy 2008;38(I):43-50.

108. Gibson PG, Saltos N, Borgas T. Airway mast cells and eosinophils correlate with clinical severity and airway hyperresponsiveness in corticosteroid-treated asthma. J Allergy Clin Immunol 2000;105:752-9.

109. Umeno E, McDonald DM, Nadel JA. Hypertonic saline increases vascular permeability in the rat trachea by producing neurogenic inflammation. Clin Invest n. 1990;85:1905-8.

II0. Kersten ET, Driessen JM, van der Berg JD, Thio BJ. Mannitol and exercise challenge tests in asthmatic children. Pediatr Pulmonol 2009;44:655-61.

III. Barben J, Roberts M, Chew N, Carlin JB, Robertson CF. Repeatability of bronchial responsiveness to mannitol dry powder in children with asthma. Pediatr Pulmonol 2003;36:490-4.

II2. Barben J, Kuehni CE, Strippoli MP, Schiller B, Hammer J, Trachsel D. Mannitol dry powder challenge in comparison with exercise testing in children. Pediatr Pulmonol 20II;46:842-8.

I13. Bjermer L, Alving K, Diamant Z, Magnussen H, Pavord I, Piacentini $G$, et al. Current evidence and future research needs for FeNO measurement in respiratory diseases. Respir Med 2014;108:830-4I.

114. Dweik RA, Boggs PB, Erzurum SC, Irvin CG, Leigh MW, Lundberg $\mathrm{JO}$, et al. An official ATS clinical practice guideline: interpretation of exhaled nitric oxide levels (FENO) for clinical applications. Am J Respir Crit Care Med 201I;184:602-15.

II5. Jacinto T, Amaral R, Malinovschi A, Janson C, Fonseca J, Alving $K$. Exhaled NO reference limits in a large population-based sample using the Lambda-Mu-Sigma method. J Appl Physiol (1985) 2018;125:1620-6.

116. Carlsten C, Aitken ML, Hallstrand TS. Safety of sputum induction with hypertonic saline solution in exercise-induced bronchoconstriction. Chest 2007;131:1339-44.

I17. Ferraz E, Borges MC, Terra-Filho J, Martinez JA, Vianna EO. Comparison of 4 AM and 4 PM bronchial responsiveness to hypertonic saline in asthma. Lung 2006;|84:34I-6.

II8. Vianna EO, Boaventura LC, Terra-Filho J, Nakama GY, Martinez JA, Martin RJ. Morning-to-evening variation in exercise-induced bronchospasm. J Allergy Clin Immunol2002;1 10:236-40.

119. McFadden ER Jr, Gilbert IA. Exercise-induced asthma. N Engl J Med 1994;330:1362-7. 